\title{
EDUCAÇÃO FÍSICA, MÍDIA E TECNOLOGIAS - INCURSÕES, PESQUISA E PERSPECTIVAS
}

\author{
Giovani De Lorenzi Pires * \\ Ari Lazzarotti Filho** \\ Mariana Mendonça Lisbôa ***
}

\begin{abstract}
RESUMO
A partir do reconhecimento das muitas interfaces da Educação Física com outras áreas do conhecimento, o texto aborda as relações que o campo vem estabelecendo com os estudos das novas tecnologias e da mídia, através do conceito de Mídia-Educação (Física). Neste sentido, apresenta as principais incursões da Educação Física brasileira junto aos sistemas digitais de informação e documentação e revisita estudos acadêmicos tomando como referência o GTT Comunicação e Mídia/CBCE e pesquisas desenvolvidas pelo LaboMidia/UFSC.

Palavras-chave: Mídia-educação. Tecnologias digitais. Pesquisa.
\end{abstract}

\section{INTRODUÇÃO}

No atual debate acadêmico da Educação Física brasileira, há pensadores que entendem que nosso campo do conhecimento/intervenção deveria ser expresso sempre no plural. Autores como Bracht (2010) e Rezer (2010), entre outros, preferem referir-se às muitas "Educações Físicas" que podem ser observadas, tanto na dimensão epistemológica quanto nas práticas sociais e pedagógicas.

No entanto, essa pluralidade de manifestações do campo parece dar-se mais por diversificação do que por superação de paradigmas. Isso implica reconhecer que tais desdobramentos se fazem por formas justapostas, e que o debate de ideias encontra-se interrompido, dando lugar a uma convivência aparentemente pacífica, ao menos na superfície, entre as várias concepções e práticas. Essa interrupção do debate epistemológico no interior do campo contribui para a cada vez maior fragmentação do(s) seu(s) objeto(s) de estudo, mantendo e ampliando a dependência do campo em relação a áreas conexas de conhecimento que sempre Ihe deram a necessária sustentação e legitimidade teórico-conceitual e metodológica (BRACHT, 2002).

Apesar disso, o quadro acima não impede que nesses diálogos interdisciplinares a Educação Física se aproprie e ressignifique projetos e propostas de outras áreas, trazendo para o seu interior possibilidades 
inovadoras para o trato com os fazeres e saberes próprios e os emprestados pelo campo.

Entre essas aproximações profícuas, importa destacar aqui a associação com a área que envolve os estudos das tecnologias de informação e comunicação e de mídia no interior do campo educacional, consolidada atualmente por meio do conceito de Mídia-Educação. Neste sentido, tem-se empregado a expressão Mídia-Educação (Física) para expressar tentativas de aproximação e apropriação teórico-metodológica daquele conceito.

A criação, em 1997, de um grupo de estudos sobre o tema no Colégio Brasileiro de Ciências do Esporte (CBCE) constitui um dos principais marcos históricos dessa aproximação. Além dele, pode-se destacar o emprego de diferentes dispositivos digitais de acesso livre para a editoração/veiculação de periódicos, gestão de eventos, disponibilização de anaise repositórios da produção científica, assunto que também será retomado mais adiante neste texto. Como consequência, aumenta o número de pesquisadores e a formação de grupos de pesquisa que se dedicam ao estudo dos atravessamentos entre Educação Física e Mídia, entre os quais tomaremos como exemplo oLaboMidia/UFSC ${ }^{1}$.

\section{EM BUSCA DE UMA BASE TEÓRICO-METODOLÓGICA: A MÍDIA- EDUCAÇÃO (FÍSICA)}

A perspectiva de uma educação para a mídia, que culminará no conceito estabelecido atualmente de Mídia-Educação ${ }^{2}$, entendida como contraponto educativo/formativo à cultura criada e veiculada pelos meios de comunicação e tecnologias, remonta aos anos cinquenta e o inicial processo de estandartização propiciado pela televisão, especialmente no Reino-Unido (BÉVORT; BELLONI, 2009).

\footnotetext{
${ }^{1}$ LaboMidia - Laboratório e Observatório da Mídia Esportiva da UFSC - www.labomidia.ufsc.br

${ }^{2}$ Corresponde a media education, em inglês; educationsaux médias, em francês; educaciónenlos médios, em espanhol, educação e media em português (Belloni, 2001).
} 
Tendo a influência de organismos internacionais em seu processo histórico ${ }^{3}$, destacadamente a Unesco ${ }^{4}$, que cunha a expressão (MídiaEducação) em 1960, esta ideia evoluiu gradativamente a partir de reflexões coletivas e práticas que se espalharam por todo o globo com o advento de novas e diferentes possibilidades técnicas de informar e comunicar. Assim, integrar as tecnologias de informação e comunicação (TICs) e a mídia nos processos educacionais, desenvolvendo sua apropriação e produção crítica e criativa, tem sido considerado condição de cidadania e direito das pessoas - e no que tange à Educação Física, as relações imbricadas entre a cultura midiática e a cultura de movimento.

Conceitualmente, entendemos possível à Educação Física tratar desse fenômeno da contemporaneidade por meio da perspectiva teóricometodológica da Mídia-Educação (Física). Esse termo expressa uma tentativa de aproximação ao conceito de Mídia-Educação, que representa o atual estágio de estudo desta área, que se encontra na interface entre educação e comunicação. Este entrecruzamento de conhecimentos forjou um campo de saberes e práticas pedagógicas que visa a capacitar os sujeitos/alunos para intervir com autonomia numa cultura amplamente imbricada às TICs.

Mídia-Educação, de acordo com Belloni (2001), Orofino (2003), Fantin (2006), Rivoltella (2009) e Girardello e Orofino (2011), objetiva, portanto, a formação de receptores e produtores/sujeitos ativos, críticos e criativos em relação à mídia e as novas tecnologias, condição para cidadania na contemporaneidade. Fantin (2006) destaca que mais do que prover e/ou proteger as crianças e jovens dos meios de comunicação de massa, há que se pensar em formas de prepará-las mais eficazmente para as responsabilidades atuais do ser criança/jovem, o que significa nos dias de hoje negociar sentidos e estabelecer relações esclarecidas e emancipadas na/com a cultura midiática

A inserção da mídia na educação deu-se, num primeiro momento, através de duas estratégias, ambas importantes, mas nem sempre associadas: i) o uso dos meios, como TV, videocassete, DVD, computador, na condição de ferramentas auxiliares do processo ensino-aprendizagem; ii) a

\footnotetext{
3 Para saber mais sobre o histórico da Mídia-Educação, ver Bevórt e Belloni (2009)

${ }^{4}$ Unesco - Organização das Nações Unidas para a Educação, a Ciência e a Cultural - www.unesco.org
} 
leitura/interpretação crítica do discurso da mídia, tomado aqui como objeto de estudo. À primeira, instrumental, faltava a necessária reflexão sobre os valores e interesses subliminares ao conteúdo que era veiculado; a segunda via transformava-se tendencialmente num discurso sobre a mídia, sem garantir a apropriação crítica e a autonomia de agir com os meios. Posteriormente, a partir da mixagem das duas estratégias e do crescimento das possibilidades interativas e criativas dos meios, consolida-se uma terceira estratégia (implícita até então): iii) produzir mídia, como blog, vídeos, jornais, etc., expressando e comunicando-se no meio, apropriando-se das diferentes linguagens midiáticas.

Como uma das precursoras desse campo no Brasil, Belloni (2001) apontou, ainda na década de 90, esta necessidade da escola adaptar-se aos "novos tempos", considerando a mídia um novo dado relacionado à cultura e à cotidianidade das pessoas, que precisava ser incluído nos processos educativos. Para a autora, educar na contemporaneidade remete analisar, refletir e se apropriar das estruturas, dinâmicas e linguagens propiciadas pela mídia e novas tecnologias em três dimensões educativas: a) educar para a mídia - compreendendo-a como objeto de estudo e temática de reflexão das práticas educativas; desvelar e esclarecer suas formas de organização e linguagens/narrativas, para a apreciação e utilização crítica; b) educar com a mídia - utilizar a mídia como ferramenta pedagógica no processo de ensinoaprendizagem, isto quer dizer, o seu uso instrumental; destaca-se a contribuição dos recursos tecnológicos/midiáticos para organização do trabalho pedagógico, e para tanto, é preciso incluí-los nas aulas, lutando pela democratização do aceso e modernização da educação; c) educar através da mídia - refere-se à produção de mídia no contexto educativo, como forma de sistematização de conhecimentos, utilização de novas linguagens (especialmente a digital), e apropriação dos processos de produção de informação/comunicação.

Acredita-se que para a efetivação da formação esclarecida à cultura midiática seja necessária a articulação das três dimensões. Isto quer dizer que é insuficiente apenas a inclusão da mídia/ TICs nas aulas, como mais uma ferramenta educativa (perspectiva muito utilizada e apontada como desafio a ser superado); é preciso também refletir sobre o processo de produção e as representações construídas/socializadas (leitura crítica), colocando a "mão na 
massa", ou seja, produzindo novas linguagens e conteúdos com os suportes comunicacionais/midiáticos.

Estas três dimensões são reconfiguradas por Rivoltella (citado por FANTIN, 2006), sendo então denominados como contextos: metodológico, crítico e produtivo.

- No contexto metodológico ou tecnológico ${ }_{1}$ a mídia-educação é considerada um recurso (instrumento) para reinventar a didática, incluindo novos suportes de aprendizagem, além do tão utilizado livro-texto.

- No contexto crítico $_{2}$ a mídia-educação tematizaria a mídia (objeto de estudo) para que os alunos fossem capazes de compreender, interpretar e avaliar seus diversos conteúdos, desenvolvendo a consciência reflexiva e responsável.

- E no contexto produtivo utilizam-se a mídia como linguagem, como forma de expressão e comunicação, ou seja, ensina-se sobre/através das linguagens da mídia, como condição da alfabetização.

Resumidamente, esta realidade permitiria, de acordo com Fantin (2006), que a práxis de Mídia-Educação desenvolvesse habilidades e competências que objetivam: 1) adotar a comunicação como modo e espaço de educação; 2) utilizar a mídia como material e ferramenta de intervenção educativa; 3) valorizar o fazer como oportunidade de aprendizagem; 4) utilizar a desconstrução e ressignificação de mensagens como metodologia importante; 5) formar o pensamento crítico.

Como campo interdisciplinar, os espaços de intervenção da Mídia Educação (Física) vão além da escola e espaços institucionalizados, ainda que seu primordial compromisso passe por estratégias escolares e políticas públicas de educação, o que inclui sua abordagem na formação inicial e continuada de professores/profissionais da Educação Física, para que seja garantida a reflexão e prática social esclarecida frente às relações com a mídia e novas tecnologias. 


\section{EDUCAÇÃO FíSICA E AS TÉCNOLOGIAS DE INFORMAÇÃO E COMUNICAÇÃO}

Como foi referido, o campo da Educação Física vem se aproximando e se apropriando de aspectos da Mídia-Educação e, nesse movimento, destacamos também o crescimento da sua relação e de ações com as TICs.

A preocupação com a documentação esportiva, com a memória, com a história e consequentemente com o seu acesso e sua democratização tem sido desenvolvida por instituições e agentes do campo da Educação Física brasileira, entre as quais podemos destacar ações que marcam essa recente história: SIBRADID ${ }^{5}, \mathrm{CEV}^{6}, \mathrm{NUTESES}^{7} \mathrm{CONBIDE}^{8}$, Grupo de Trabalho Temático (GTT)Comunicação e Mídia do $\mathrm{CBCE}^{9}$, Centros de Memória ${ }^{10}$, cujos acervos vem sendo digitalizados e disponibilizados,além da criação de laboratórios/grupos que desenvolvem pesquisa com essa temática.

Mas talvez a experiência de maior impacto tenha sido o crescente alinhamento da Educação Física à política de acesso livre do $\mathrm{IBICT}^{11}$ e suas soluções tecnológicas, todas "Open Source", de acordo com os princípios do movimento mundial de acesso livre ao conhecimento.

O movimento de acesso livre à informação científica é caracterizado por duas principais iniciativas: Open Access (OA) e Open ArchivesInitiative(OAI). Para Ferreira (2008), a OAl é o elemento técnico de interoperabilidade dos sistemas enquanto que a OA é a base política que fundamenta o acesso livre à informação científica. $O$ acesso livre consolida-se com a disponibilização integral e gratuita na Internet de literatura de caráter científico, permitindo a

\footnotetext{
5 Sistema Brasileiro de Documentação e Informação Desportiva, da EEFFTO/UFMG www.sibradid.eeffto.ufmg.br/

${ }^{6}$ Centro Esportivo Virtual - www.cev.org.br

${ }^{7}$ Núcleo Brasileiro de Teses e Dissertações em Educação Física, vinculado à Universidade Federal de Uberlândia www.nuteses.ufu.br

${ }^{8}$ Congresso Brasileiro de Informação e Documentação Esportiva - 1a edição (Brasília, 2006) e 2a edição (Belo Horizonte, 2008). Anais disponíveis no CEV, respectivamente em: http://cev.org.br/eventos/conbide-congresso-brasileiro-informacao-documentacaoesportiva/trabalhos/e http://cev.org.br/eventos/ii-conbide/trabalhos/.

${ }^{9}$ www.cbce.org.br/br/gtt/comunicacao-e-midia/

${ }^{10}$ Um exemplo é o CEME - Centro de Memória do Esporte, da Escola de Educação Física da UFRGS http://www.esef.ufrgs.br/ceme/

${ }^{11}$ Instituto Brasileiro de Informação em Ciência e Tecnologia, do Ministério da Ciência e Tecnologia $<$ www.ibict.br $>$.
} 
qualquer pessoa a possibilidade de pesquisar, consultar, descarregar, imprimir, copiar e distribuir fontes de informação científica (sem fins comerciais).

Os principais documentos sobre o acesso livre são a "Iniciativa de Acesso Livre de Budapeste" (Budapest Open Access Initiative), de 2002, a Declaração de Berlim sobre o Acesso Livre ao Conhecimento nas Ciências e Humanidades (Berlin Declaration on Open Access to Knowledge in the Sciences and Humanities), de 2003 e o Manifesto Brasileiro de Apoio ao Acesso Livre a Informação Científica (2005). Estas ações apontam para mudanças profundas no processo de difusão do conhecimento e indicam uma ruptura com a política de veiculação científica tradicional, estruturada a partir da lógica do mercado editorial.

Segundo Kuramoto (2006), a OAI tem como meta principal contribuir, de forma enfática, para a transformação dos modos de comunicação científica. A linha de ação proposta dessa transformação é a definição de aspectos técnicos e de suporte organizacional de uma estrutura de publicação científica aberta. Dessa forma, os princípios básicos que regem a OAl são o auto arquivamento, a revisão pela comunidade científica e a interoperabilidade entre ferramentas, criando dessa forma um sistema de provedores de dados e provedores de serviços que operam em conjunto. Esta linha de ação busca o compartilhamento e a facilitação na agregação de dados através do Protocol for MetadataHarvesting $(\mathrm{PMH})$, protocolo que garante o elemento técnico de dados sobre dados, ou seja, os metadados.

Os provedores de dados representam a base de todo o sistema da OAI, pois são considerados os insumos para os demais serviços. Como exemplo, podemos citar os softwares de código-fonte aberto, cuja tradução e customização foi disponibilizada pelo IBICT e atravésdos quais a Educação Física tem criado suas estratégias operacionais: Sistema Eletrônico de Editoração de Revistas - SEER; Sistema Online de Apoio a Congressos SOAC; Banco de Teses e Dissertações - TEDE; Repositórios Digitais DSPACE.

O Sistema Eletrônico de Editoração de Revistas (SEER) é um software desenvolvido para a construção e gestão de publicações periódicas eletrônicas. Esta ferramenta contempla ações essenciais à automação das atividades de editoração de periódicos científicos, baseado no software desenvolvido pelo 
PublicKnowledge Project (Open Journal Systems) da Universidade British Columbia (http://pkp.sfu.ca/ojs/).

No campo da Educação Física, o SEER se firmou como uma ferramenta de gestão das suas principais revista, garantindo assim, o acesso livre a toda a produção e talvez um dos quesitos que mais a qualificaram, quando do primeiro curso para editores da área, realizado pelo IBICT durante o I CONBIDE (Brasilia/DF, 2006).

As revistas brasileiras do campo da Educação Física que operam atualmente no SEER, conforme consta na pagina do $\mathrm{IBICT}^{12}$,são:

1. Arquivos em Movimento - http://www.eefd.ufri.br/arquivos

2. Brazilian Journal of Biomechanics http://143.107.39.184/ojs/index.php/rbb/index

3. Cadernos de Educação Física - Estudos e Reflexões - http://erevista.unioeste.br/index.php/cadernoedfisica/index

4. Conexões - http://polaris.bc.unicamp.br/seer/fef/index.php

5. Journal of Exercise and Sport Sciences

http://ojs.c3sl.ufpr.br/ojs2/index.php/jess/

6. Movimenta - http://www.nee.ueg.br/seer/index.php/movimenta

7. Movimento e Percepção - http://www.unipinhal.edu.br/movimentopercepcao

8. Pensar a Prática - http://www.revistas.ufg.br/index.php/fef

9. Revista Brasileira de Ciências do Esporte http://www.rbceonline.org.br/revista/index.php

10.Revista Brasileira de Cineantropometria e Desempenho Humano http://www.rbcdh-online.ufsc.br/

11. Revista de Educação Física da UEM

http://periodicos.uem.br/ojs/index.php/RevEducFis/index

12.Motrivivência - http://www.periodicos.ufsc.br/index.php/motrivivencia/index

13.Motriz - http://cecemca.rc.unesp.br/ojs/index.php/motriz

14.Revista Movimento - http://www.seer.ufrgs.br/index.php/Movimento/index

${ }^{12}$ Outros periódicos da área utilizam o SEER, mas ainda não foram catalogados na lista de revistas informadas pelo IBICT. 
O Sistema On-line de Apoio a Congressos (SOAC) é um sistema de gerenciamento de congressos científico que garante as etapas de gestão do congresso: inscrição dos participantes, o processo de submissão e avaliação dos papers e a publicação em forma de anais. Atualmente, apenas o Colégio Brasileiro de Ciências do Esporte (CBCE)implementou o SOAC para gestar os congressos sob sua chancela e em 2011, com mais de dez congressos já gerenciados, disponibiliza toda a sua memória e os anais desses eventos constituindo um acervo de aproximadamente mil papers (http://www.rbceonline.org.br/congressos/).

O TEDE é um software que tem como objetivo proporcionar a implantação de bibliotecas digitais de teses e dissertações nas instituições de ensino e pesquisa e sua integração à Biblioteca Digital de Teses e Dissertações - BDTD nacional. Este sistema está implantado na quase totalidade dos cursos de Pós-Graduação em Educação Física brasileiros, facilitando a recuperação da informação das dissertações e teses defendidas no Brasil, via metadados. Algumas universidades possuem seus próprios bancos de teses e dissertações, como é o caso da Unicamp, mas ao mesmo tempo, utilizam o protocolo OAI, podendo ser gerado novos serviços. Podemos acessar esse banco de dados em http://bdtd.ibict.br/.

Por fim, o sistema DSPACE possibilita a reposição de qualquer objeto digital já divulgado e tem como finalidade garantir a memória institucional e a preservação da produção intelectual de uma organização ou de uma dada temática do conhecimento (http://dspace.ibict.br/index.php?option=com frontpage\&ltemid=1). Por influencia do IBICT, há atualmente nas universidades brasileiras 0 desenvolvimento de uma política de implantação de repositórios a partir das unidades acadêmicas, que passam a disponibilizar a produção dos seus pesquisadores para acesso livre; assim, espera-se que em breve haja um grande acervo digital nacional. Exemplos disso já podem ser visto na UFRGS<http://www.lume.ufrgs.br> $>$ e $\quad$ na UnB $<$ http://repositorio.bce.unb.br/handle/10482/28>.

No campo da Educação Física, Esporte e Lazer, foram implantados recentemente dois repositórios institucionais, ambos ligados a programas do Ministério do Esporte. O primeiro deles é o Projeto Memória do Programa 
Segundo Tempo ${ }^{13}$,fruto de uma parceria do Ministério do Esporte com o Centro de Memória do Esporte (CEME) da Escola de Educação Física da Universidade Federal do Rio Grande do Sul (UFRGS). O projeto busca construir registros sobre a memória do PST, gerando e divulgando informações de natureza acadêmica e históricas, entre outras. Visa, sobretudo, a "transmitir às gerações do presente $\mathrm{e}$ do futuro conhecimentos sobre um projeto específico cuja efetivação vem marcando o cenário das políticas públicas de esporte no Brasil", e pode ser acessado a partir do seguinte endereço: http://www.repositorioceme.ufrgs.br/handle/123456789/2.

Outro exemplo é o Repositório Institucional da Rede CEDES (RIRC), parceria entre o Ministério do Esporte e o LaboMidia/UFSC.O RIRC (http://www.labomidia.ufsc.br/redecedes/)tem como objetivo reunir, organizar, preservar e disponibilizar os arquivos digitais referentes à produção científica decorrente das pesquisas realizadas por pesquisadores e grupos integrantes da Rede CEDES ${ }^{14}$.

Entre os dois repositórios do campo da Educação Física, Esporte e Lazer aqui apresentados, a principal diferença talvez seja o fato de que o RIRC prioriza a construção coletiva do seu acervo, com ênfase no auto arquivamento por parte dos próprios pesquisadores, cujo objetivo é investir na mudança da cultura de divulgação científica, muito limitada aos cânones das políticas de periódicos científicos.

Os provedores de serviços desenvolvem ações a partir dos provedores de dados como construção de coleções específicas, criação de índices bibliométricos, índices de impacto, etc. No campo da Educação Física, o NUTESES faz parcialmente esse papel, mas o desenvolvimento dos provedores de serviço é ainda pouco explorado. Com o avanço dos sistemas (provedores de dados), é possível já pensarmos na implantação de projetos

\footnotetext{
13 Projeto Segundo Tempo é uma ação programática do Ministério do Esporte, que tem como propósito democratizar o acesso à prática e à cultura do esporte de forma a promover 0 desenvolvimento integral, como fator de formação da cidadania e melhoria da qualidade de vida, sobretudo em áreas de vulnerabilidade social.

${ }^{14}$ Rede CEDES é uma ação programática do Ministério do Esporte, cujo objetivo é incentivar e financiar a pesquisa, a produção e a veiculação do conhecimento relativo a políticas públicas em Esporte e Lazer, notadamente em inclusive para subsidiar a ação do Projeto Segundo Tempo.
} 
que possam gerar serviços como, por exemplo, um sistema que agregue numa única interface todos os provedores de dados, como o apresentado por Lazzarotti Filho (2009).

\section{TRAJETÓRIAS: DO “GRUPO DE SANTA MARIA” AO GTT COMUNICAÇÃO E MÍDIA/CBCE}

Um movimento de discussão interna ao campo, que emergiu a partir da década de 80 do século passado, levou a Educação Física buscar superar as tradicionais abordagens biologicistas e esportivizadas, aproximando-se para isso de áreas das ciências humanas e sociais. Entre essas, uma das articulações precursoras foi a relação estabelecida com os estudos dos meios de comunicação, cujo pioneirismo devemos ao que se denominou "Grupo de Santa Maria", ligado ao Centro de Educação Física e Desportos da Universidade Federal de Santa Maria (PIRES et al., 2008).

No decorrer dos anos 90, o grupo de pesquisa do CEFD/UFSM, batizado oficialmente como Laboratório de Comunicação, Movimento e Mídia na Educação Física (LCMMEF), criou um periódico próprio (Caderno do LCMMEF; infelizmente, interrompido e não disponível online), uma linha de pesquisa junto ao Programa de Pós-graduação em Ciência do Movimento Humano do CEFD/UFSM e um núcleo temático de Comunicação Esportiva na INTERCOM (Sociedade Brasileira de Estudos Interdisciplinares de Comunicação Social).

A produção do Grupo de Santa Maria concentrou-se no jornalismo esportivo, acolhendo um número maior de pesquisadores da comunicação social do que de professores de Educação Física. Este fato o levou à aproximação com a INTERCOM, mas custou-Ihe, em contrapartida, pouca produção e baixa visibilidade no campo específico da Educação Física, sobretudo no âmbito escolar.

Na sequência, é possível considerar que a principal manifestação de reconhecimento da importância dos estudos ligados ao campo denominado Mídia-Educação na Educação Física, é o fato deles terem sido admitidos como referência na articulação de um grupo temático específico no Colégio Brasileiro de Ciências do Esporte (CBCE). 
No ano de 1997, o CBCE promoveu uma significativa reforma na estrutura científica do $\operatorname{CONBRACE}^{15}$, com a criação de grupos de trabalho temáticos (GTTs), que posteriormente foram incorporados como instâncias organizativas do Colégio. Um dos GTT/CBCE que permanece em funcionamento desde aquela data é o de Educação Física, Comunicação e Mídia, que conta com uma comissão científica própria, com a coordenação de dois dos seus membros (LEIRO; PIRES; BETTI, 2007).

Um número razoável de pesquisadores tem participado do GTT, tanto no CONBRACE quanto nos congressos regionais da entidade. O número de trabalhos veiculados em oito (08) edições do GTT em CONBRACEs (no período 1997-2011) pode dar uma dimensão talvez mais precisa da sua crescente importância: foram apresentados208 artigos (média de 26 trabalhos a cada edição), com os textos completos publicados na íntegra nos anais dos eventos.

A atual ementa do GTT, que orienta os pesquisadores e demarca os interesses de estudo, procura explicitar de forma clara a intenção em acolher diferentes abordagens ao tema da Educação Física e Mídia (LEIRO; PIRES; BETTI, 2007):

\footnotetext{
Estudos relacionados à comunicação, mídia e documentação no âmbito da Educação Física/Ciências do Esporte; análise crítica e interpretação dos processos de produção, difusão e recepção de informação das mídias e tecnologias educacionais, e suas implicações políticas, econômicas, culturais e pedagógicas.
}

Entre outras pesquisas centradas na produção do grupo (PIRES; BITENCOURT, 1999; PIRES, 2003), investigação sobre a primeira década de existência do GTT Comunicação e Mídia/CBCE(período 1997-2007, seis edições), apresenta uma análise descritiva dos 135 trabalhos publicados nos anais daqueles eventos, a partir das seguintes categorias dos estudos: veículo midiático referido, tema ou conteúdo da Educação Física abordado, bases teórico-conceituais de referência e desenhos metodológicos adotados (AZEVEDO; COSTA; PIRES, 2008).

\footnotetext{
${ }^{15}$ Congresso Brasileiro de Ciências do Esporte, atualmente realizado a cada dois anos, junto com o Congresso Internacional de Ciências do Esporte (CONICE).
} 
Algumas considerações deste estudo permitem perceber a hegemonia incontestável do esporte como principal tema/conteúdo de estudo, seguido de perto pelos estudos relativos à formação profissional e propostas de intervenção com essa temática na Educação Física escolar, o que soa como noticia bem-vinda e alvissareira, pois demonstra o interesse dos profissionais da área em levarem essa discussão para o interior dos cursos de formação de professores e para a prática pedagógica nas escolas.

Quanto aos veículos midiáticos referidos nas pesquisas, prevalecem a televisão e a mídia em geral (quando não discriminados os meios abordados); em segundo lugar, os jornais impressos passaram a dividir a colocação com estudos sobre temas decorrentes da popularização das chamadas novas mídias, com suportes digitais, como: portais, homepages, jornais online, games, blogs, redes sociais, etc.

$\mathrm{Na}$ análise dos quadros teóricos de referência produzidos nos textos analisados, percebe-se uma busca por melhor entendimento conceitual sobre as interfaces entre Educação Física e mídia, destacando-se aqui os estudos culturais críticos (sobretudo, sobre a indústria cultural e a sociedade do espetáculo) e sobre técnicas midiáticas de produção e veiculação da informação, do entretenimento e da publicidade, articulados a temas da Educação Física, como os conceitos de mediação, recepção, agendamento, persuasão, etc.

Finalmente, no que se refere aos desenhos metodológicos dos estudos observados, predominam, ainda, os estudos classificados como análise de produtos da mídia, que são aqueles em que matérias e programas de diferentes gêneros, o que se chamou discurso midiático-esportivo (quando relacionado a temas da Educação Física), são descritos e analisados. Nesta categoria também podemos comemorar o crescimento contínuo de estudos descritivos e de pesquisas participativas, o que leva a crer que novas abordagens da temática vem sendo implementadas na prática pedagógica, notadamente na escola (e relatadas/analisadas nos estudos).

Além dos trabalhos apresentados em eventos científicos, a produção em Mídia-Educação Física circula também em alguns livros, capítulos e periódicos da área. Quanto a estes últimos, vale destacar aqueles que dedicaram números ou seções temáticas exclusivas ao assunto, como a Pensar a Prática 
(v. 10, n.2, 2007 - http://revistas.ufg.br/index.php/fef), a Motrivivência (ano XII, n.17, 2001; ano XIII, n.18, 2002; ano XXI, v.34, 2010 - todos disponíveis emhttp://www.periodicos.ufsc.br/index.php/motrivivencia/index) e a Revista Brasileira de Ciências do Esporte (v.26, n.2, 2005 http://www.rbceonline.org.br/revista/index.php).

Como o tema da Mídia-Educação Física revela-se ainda incipiente no campo da Educação Física, também são ainda poucos os grupos de pesquisa dedicados prioritariamente aos estudos do tema, observando-se também a produção de muitos pesquisadores independentes. Um dos grupos que vem se consolidando no campo é o LaboMidia - Laboratório e Observatório da Mídia Esportiva, localizado no Centro de Desportos (CDS) da Universidade Federal de Santa Catarina (UFSC), com núcleos e pesquisadores associados em universidades de diversos estados brasileiros (www.labomidia.ufsc.br). É, pois, sobre este grupo que tratamos a seguir, conhecendo sua estrutura e revisitandoalguns dos seus principais estudos emMídia-Educação (Física)

\section{LaboMidia/UFSC: PROJETO E REALIZAÇÕES}

O LaboMidia foi criado no ano de 2003, junto à estrutura acadêmicoadministrativa do Centro de Desportos da UFSC, sendo ligado também ao $\mathrm{NEPEF}^{16}$ e ao PPGEF ${ }^{17}$. Sua criação ocorreu como estratégia mobilizadora de um grande projeto acadêmico, cujo propósito é inserir a cultura midiática como ferramenta e como objeto de estudo na formação inicial e continuada em Educação Física. Ele contempla iniciativas como a oferta de disciplinas específicas na graduação e na pós-graduação, projetos de extensão para capacitação de professores das redes públicas, soluções tecnológicas para as atividades de ensino, pesquisa e extensão, oficinas oferecidas à comunidade do CDS para uso dos equipamentos tecnológicos disponibilizados, edição de vídeos, etc.

A proposta do LaboMidia contempla uma dupla inserção acadêmica: como laboratório didático e de apoio para o ensino, pesquisa e extensão do

\footnotetext{
${ }^{16}$ Núcleo de Estudos Pedagógicos em Educação Física - CDS/UFSC

${ }^{17}$ Programa de Pós-Graduação em Educação Física - CDS/UFSC
} 
CDS, e como grupo de estudo destinado à pesquisa na interface Educação Física e Mídia, sendo que é na direção desta segunda dimensão que daremos continuidade à exposição do LaboMidia.

Antes, porém, importa destacar alguns dados e ações gerais do LaboMidia, como o apoio e a ancoragem que o laboratório dá a projetos acadêmicos como a revista Motrivivência e o Repositório Institucional da Rede CEDES, já referidos, além do blog Observatório da Mídia Esportiva e do blog do professor Silvino Santin, todos com acesso pela pagina do LaboMídia (www.labomidia.ufsc.br).

O LaboMidia é formado por docentes, pós-graduandos e graduandos da UFSC e de outras instituições de ensino de Santa Catarina e de diversos outros estados brasileiros, organizados em núcleos e ou de forma individual, cuja participação se dá de diferentes maneiras (presenciais e virtuais) e, uma vez por ano, no encontro nacional dos pesquisadores do Observatório da Mídia Esportiva (ENOME).Na pós-graduação, o LaboMidia já contribuiu na formação de 21 mestres e um doutor, cujos trabalhos finais estão disponíveis online no pagina do grupo. Além disso, há investimento na formação de graduandos, através de projetos de iniciação científica, e na formação mútua e cooperativa dos pesquisadores em diferentes estágios acadêmicos e profissionais, por meio de pesquisas coletivas de observatório, como as de análise da cobertura midiática em eventos esportivos regionais, nacionais e internacionais.

Apresentada a estrutura, o escopo e algumas ações do laboratório, passamos a uma tentativa de caracterização da produção do grupo, tendo como referência para a classificação dos estudos uma organização em categorias provisórias, que toma por base o tipo de abordagem procedido por eles. Assim, podemos destacar os seguintes agrupamentos de estudos:

1. Estudos observacionais-descritivos e de recepção: pesquisas que procuraram compreender como determinados grupos sociais, principalmente escolares, percebem, interagem e produzem sentidos relativos os meios e seus discursos;

2. Mediações/interlocuções pedagógicas: estudos de pesquisa-ação e/ou participativa, que promovem estratégias de tematização da mídia/tecnologias na Educação Física escolar e na formação de professores da área; 
3. Análise de produtos da mídia: investigações voltadas para 0 acompanhamento e análise do discurso midiático-esportivo a partir de seus produtos e meios, como programas, jornalismo, cobertura de eventos, etc.

4. Cultura digital e aprendizagem: estudos que vem enfocando as possibilidades e limites da interação entre a Educação Física e as novas tecnologias digitais.

Para ilustrar a produção expressa nessas categorias preliminares, apresentam-se a seguir alguns exemplos de cada uma delas, como breve descrição dos objetivos, metodologias e "achados" das pesquisas realizadas.

Entre os estudos observacionais e de recepção, é interessante destacar os trabalho de Antonio Galdino da Costa (2006) e de Scheila Antunes (2007), ambos com jovens escolares do ensino médio, ambos em escolas públicas, uma em São José e outra em Florianópolis/SC. Galdino da Costa partiu da hipótese de que há uma comunicação expressa e compreendida no âmbito das culturas juvenis (PAES, 2003)que acontece através da moda e indumentária, o que denominou "identidades corporais provisórias". Seu estudo baseou-se na observação de como vão sendo formados os grupos de jovens recémchegados a uma escola exclusivamente de ensino médio e qual o papel exercido pelas roupas e adereços na aproximação e composição destes grupos. O registro fotográfico semanal, em vários momentos e espaços da escola, permitiu compreender que, além de os grupos se constituírem pela aparência, ela é também motivo de exclusão entre os jovens, que interpretam hábitos e interesses pelo tipo de indumentária utilizada, fazendo da diferença manifestação nem sempre sutil de preconceitos. A técnica de grupos focais, com a apresentação das fotografias aos jovens, permitiu a reflexão sobre suas socializações no interior da escola, tanto em espaços didáticos (sala de aula, ginásio, quadra) quanto informais da escola.

Scheila Antunes empreendeu estudo de recepção com jovens do ensino médio praticantes de futebol como atividade escolar obrigatória (Educação Física), cujo objetivo foi compreender como eles atribuíam significados a determinadas características do discurso midiático-esportivo produzido na 
cobertura de uma Copa do Mundo da FIFA e o papel de agência mediadora (MARTIN-BARBERO, 2003) exercida pela Educação Física escolar. Dos dados colhidos em estratégias como entrevistas, grupos focais e observações participantes, dois eixos principais indicados pelos alunos abriram caminhos para a análise: a percepção da personificação e ancoragem da cobertura midiática na figura do ídolo e das estreitas relações entre futebol, mídia e publicidade. Também se percebeu que, apesar do interesse manifesto dos alunos pelo tema da Copa do Mundo, a Educação Física e a escola como um todo perdeu a oportunidade de pautar $\mathrm{o}$ assunto em suas intervenções pedagógicas, ficando restrito aos comentários informais de alunos e professores pelos corredores da escola.

Os estudos de mediação/interlocução escolar desenvolvidos baseiam-se sobretudo em elementos da pesquisa-ação (BARDIN, 2009), cujo propósito é, em geral, verificar as possibilidades teórico-metodológicas da Mídia-Educação (Física) para capacitação de professores e/ou alunos, visando uma interlocução mais esclarecida e autônoma com a mídia, no que se refere a aspectos relacionados à Educação Física. Entre os estudos empreendidos nessa direção, pode-se citar o de Marcio Romeu Ribas de Oliveira (2004) e o de Paula Bianchi (2009), ambos realizados em Florianópolis/SC.

A pesquisa de Marcio Romeu fundamentou-se no conceito benjaminiano de experiência com o objetivo de refletir sobre a inserção de meios técnicos na produção de imagens no âmbito da Educação Física escolar, partindo do princípio que seus atores se percebem envolvidos no cenário da cultura mediatizada. Desenvolvida na forma de oficinas pedagógicas de reflexão, capacitação e experiências de produção de imagens (fotografia e vídeo), a pesquisa foi realizada com alunos das séries finais do ensino fundamental de uma escola pública, cujas produções finais mostram possibilidades aumentadas dos alunos quanto à compreensão da produção midiática.

A pesquisa realizada por Paula Bianchi visou à promoção de capacitação de professores de Educação Física da rede pública municipal de Florianópolis para o uso didático das tecnologias digitais disponíveis nas escolas. Estudo preliminar mostrou que estes professores não eram contemplados nos projetos de formação oferecidos pelo Núcleo de Tecnologia Educacional da Secretaria Municipal de Educação de Florianópolis (NTE/SME) 
e, em consequência disso, não desfrutavam dos recursos disponíveis nas salas informatizadas das escolas municipais. A partir dessa constatação, a autora propôs uma interlocução de saberes e fazeres da cultura escolar, que proporcionasse um pensar-agir-refletir sobre conteúdos da Educação Física escolar, na perspectiva das TICs, desenvolvida de forma colaborativa e cooperativa. A ferramenta didático-tecnológica escolhida foram os blogs, cuja construção foi feita em interação com os alunos (turmas de diversas séries do ensino fundamental, em várias escolas), para o registro, socialização e integração das ações pedagógicas realizadas pelas turmas/escolas envolvidas no estudo, a partir de um conteúdo comum a todas (lazer - jogos e brincadeiras).

Os estudos de análise de produtos da mídia configuram-se como a metodologia preferencial das pesquisas de observatórios da mídia (CHRISTOFOLLETI; MOTTA, 2008). Nesse sentido, o LaboMidia tem realizados investigações coletivas sobre o discurso midiático regional e nacional na cobertura de eventos esportivos como Jogos Abertos catarinenses (PIRES et al., 2008), Jogos Pan-americanos (PIRES et al., 2009) e Copa do Mundo FIFA (PIRES et al., 2011). Diferentes meios e tipos de abordagens foram selecionados para a compreensão de aspectos como a imbricação entre esporte e publicidade, o recurso a argumentos identitários e nacionalistas nas narrativas, estratégias de agendamento da cobertura a ser feita, entre outros.

Além dos trabalhos coletivos, a pesquisa de Fabio Messa (2010) também se caracteriza como análise de produto da mídia, nesse caso, das charges do jornalismo esportivo impresso. Seu estudo acompanhou a cobertura da participação do Avaí Futebol Clube na série $A$ do campeonato brasileiro de 2009, através da narrativa de charges de três jornais de circulação estadual. Pela analise semiótico-discursiva, pode-se perceber como as charges, com humor, pautam as rodadas vindouras, repercutem os resultados, ressaltam situações críticas, estabelecem comparações com clubes rivais, etc., através de uma linguagem simbólica e interdiscursiva.

Os estudos relacionados à cultura digital e aprendizagens são mais recentes e refletem o desenvolvimento acelerado dos aparatos tecnológicos digitais a serviço da aprendizagem, situação ainda pouco difundida na Educação Física. Entre estes, podemos destacar a etnografia virtual 
empreendida por Rogério Santos Pereira (2009) no game Second Life; a análise feita por Rodrigo Ferrari (2012) a partir dos gestores e pesquisadores da rede CEDES sobre a criação do repositório digital da rede; a proposta de Victor A. Azevedo (2011) para a criação/validação de metodologia de análise de jogos eletrônicos para uso educacional; o estudo de André Quaranta (2011) sobre a formação de professores de Educação Física em curso de licenciatura na modalidade EAD; e o uso, nas aulas de Educação Física, dos computadores do programa Um Computador do Aluno, no Brasil e no Uruguai, pesquisa realizada por Verônica Gabriela Piovani (2012). Sobre estes dois últimos estudos, apresentam-se mais alguns elementos.

Quaranta tomou como referência o momento de inserção de alunos de um curso de Educação Física modalidade EAD na cultura escolar, através do primeiro estágio supervisionado dos alunos de um polo de apoio presencial no interior da Bahia. Em estudo de múltiplos casos, objetivou compreender o significado das primeiras experiências docentes de acadêmicos, relacionandoas com o currículo de um curso cujas características fogem do padrão das demais graduações em Educação Física, área que se identifica com as chamadas práticas corporais, aqui substituídas pela tecnologia (plataforma moodle). As considerações permitem perceber que o estágio do curso revela certas fragilidades curriculares dessa modalidade de ensino, além da absoluta falta de estrutura de supervisão e acompanhamento, o que torna esse momento tão significativo da formação em apenas um cumprimento formal da carga horária mínima exigida.

Verônica Piovani realizou pesquisa cujo objetivo foi verificar possibilidades e limites para a inserção metodológica do computador nas aulas de Educação Física, em escola do interior catarinense e de Montevideo/Uruguai, no âmbito dos programas ProUCA (no Brasil) e CEIBAL (no Uruguai). Para tanto, junto com professores das escolas, planejou $\mathrm{e}$ desenvolveu um intercâmbio pedagógico e cultural dos alunos, através de experiência com jogos e brincadeiras da cultura popular dos dois países, socializados e compartilhados digitalmente por meio da criação de blogs. Suas conclusões apontam para uma situação paradoxal: em que pese o interesse e a grande motivação iniciais dos alunos, eles terminam perdendo o foco à medida que os limites de infraestrutura escolar e do próprio meio (computador 
pessoal ligado à internet) passam a demandar tempo excessivo e dificuldades operacionais para realização das atividades planejadas no estudo. Isso demonstra que não basta a distribuição de ferramentas (no caso, o computador) para garantir o sucesso das políticas de inserção digital, senão houver um conjunto de outros aportes, como infraestrutura escolar, capacitação dos professores, manutenção dos computadores, etc.

\section{CONSIDERAÇÕES FINAIS}

A Educação Física brasileira, como campo de fronteira cujo corpo de conhecimentos e práticas ainda é amplamente referenciado em áreas que se colocam justapostas no seu interior, tem buscado construir sua autonomia pedagógica e sua legitimação acadêmica neste movimento de tensão interdisciplinar (BRACHT, 2003). Neste sentido, entendemos que as interações estabelecidas com os diversos campos de conhecimento precisam ser melhor elaboradas, visando produzir novos saberes e fazeres que tenham organicidade e respondam às especificidades da Educação Física, quaisquer que sejam seus quadros conceituais de referência.

Isso posto, vemos que as ações empreendidas até aqui na direção de estabelecer uma associação virtuosa com a Mídia-Educação, embora ainda incipientes, vem sendo bem sucedidas e tem contribuído para que a Educação Física enfrente os desafios contemporâneos da cientificidade sem abrir mão do seu compromisso de intervenção social e pedagógica, situando-se em dia com a cultura do seu tempo. Entendemos que um processo coletivo e cooperativo de produção do conceito de Mídia-Educação (Física) poderá proporcionar sólidas bases teórico-metodológicas para que a mídia e as novas tecnologias digitais sejam apropriadas e ressignificadas na sua interface com os conteúdos da Educação Física.

No que se refere ao uso das tecnologias para o registro e difusão do conhecimento, como tentamos demonstrar com os exemplos dos sistemas abertos de periódicos e anais online de eventos, das bibliotecas e repositórios digitais, podemos considerar que a Educação Física tem tomado uma posição bastante avançada, que chega a distingui-la entre outras áreas do conhecimento, especialmente entre as do campo das ciências sociais e 
humanas. Da mesma forma, a tematização dos estudos sobre comunicação e mídia em grupo de trabalho na principal sociedade científica da área, com crescimento constante do número de trabalhos, ajuda a trazer para a Educação Física um olhar atento e até certo ponto inovador em relação aos assuntos relacionados à mídia e tecnologias digitais.

Entendemos que esses indicadores são plenamente satisfatórios para a empreitada acadêmica que estamos propondo. Todavia, a existência de alguns grupos de estudo e de pesquisadores voltados para essa temática como o LaboMidia/UFSC ainda não é suficiente para considerarmos que estamos em processo seguro de consolidação da Mídia-Educação (Física) como um subcampo da Educação Física. O longo percurso que ainda se percebe à frente precisa ser pavimentado com a presença mais incisiva dos estudos sobre mídia e tecnologias nos currículos dos cursos de graduação, nas ações de formação continuada do professor em serviço e, sobretudo, nos programas de pós-graduação em Educação Física, ainda amplamente dominados pela lógica produtivista e calcados em pressupostos das ciências naturais.

\section{REFERÊNCIAS}

ANTUNES, Scheila E. O "país do futebol" na copa do mundo: estudo de recepção ao discurso midiático-esportivo com jovens escolares. Dissertação (Mestrado em Educação Física). Florianópolis, PPGEF/UFSC, 2007.

AZEVEDO, Victor A. Jogos eletrônicos e educação: construindo um roteiro para sua análise pedagógica.Dissertação (Mestrado em Educação). Florianópolis, PPGE/UFSC, 2011.

AZEVEDO, Victor A.; GALDINO DA COSTA, Antonio; PIRES, Giovani De L. Dez anos do GTT Educação Física, Comunicação e Mídia (CONBRACE/CBCE): análise de percurso e tendências. Congresso Brasileiro de Informação e Documentação Esportiva - CONBIDE, 2, Anais... Belo Horizonte: EEFFTO/UFMG; Ministério do Esporte, 2008. 
BARDIN, Lawrence. Análise de conteúdo,2 ed., revista e ampliada. Lisboa: Edições 70, 2009.

BELLONI, Maria Luiza. O que é mídia educação. Campinas: Autores Associados, 2001.

BÉVORT, E.; BELLONI, M. L. Mídia-educação: conceitos, história e perspectivas. Educação \& Sociedade, v.30, n.109, p.1081-1102, dez/2009.

BIANCHI, Paula. Formação continuada em Mídia-Educação(Física): ações colaborativas na rede municipal de Florianópolis/SC. Dissertação (Mestrado em Educação Física), PPGEF/UFSC. Florianópolis: 2009.

BRACHT, Valter. A Educação Física brasileira e a crise da década de 1980: entre a solidez e a liquidez. In: MEDINA, João Paulo. A Educação Física cuida do corpo e... mente, 25 ed., revista e ampliada. Campinas: Papirus, 2010.

. Educação Física e ciência: cenas de um casamento (in)feliz. ljuí: Ed. UNIJUI, 2003.

CHRISTOFOLETTI, Rogério; MOTTA, Luiz Gonzaga (orgs.). Observatórios de mídia: olhares da cidadania. São Paulo: Paulus, 2008.

FANTIN, Mônica. Mídia-Educação: conceitos, experiências, diálogos Brasil-Itália. Florianópolis: Cidade Futura, 2006.

FERRARI, Rodrigo D. Gestão da informação e conhecimento emesporte e lazer: o caso do repositório institucional da rede CEDES.Dissertação (Mestrado em Educação Física). Florianópolis, PPGEF/UFSC, 2012.

GALDINO DA COSTA, Antonio. Moda/indumentária em culturas juvenis: símbolos de comunicação e formação de identidades corporais 
provisórias em jovens de ensino médio.Dissertação (Mestrado em Educação Física). Florianópolis, PPGEF/UFSC, 2006.

GIRARDELLO, Gilka; OROFINO, Maria Isabel. Una mirada sobre educación y mediosen Brasil.Infoamérica,n. 5, p. 113-122, 2011.

KURAMOTO, Hélio. Informação científica: proposta de um novo modelo para o Brasil. Ciência da Informação (Brasília), v.35 n.2, 22/08/2006.

LAZZAROTTI FILHO, Ari. Sistema Inteligente de Recuperação da Informação da Educação Física e Ciências do Esporte. Congresso Goiano de Ciências do Esporte, 6, Anais... Goiânia: 2009. p. 1-4.

LEIRO, Augusto Cesar R.; PIRES, Giovani De Lorenzi; BETTI, Mauro. Notas sobre o GTT de Comunicação e Mídia do CBCE: história, sujeitos e desafios estratégicos. In: LINHALES, Meily A.; CARVALHO, Yara M. (orgs.). Política científica e produção do conhecimento em Educação Física. Goiânia: CBCE, 2007, p. 161-173.

MARTÍN-BARBERO, Jesus. Dos meios às mediações: comunicação, cultura e hegemonia.2 ed. Rio de Janeiro: Ed. UFRJ, 2003.

MESSA, Fabio C. Os destinos do leão: um estudo semiótico-discurssivo das charges jornalísticas sobre o Avaí futebol clube no campeonato brasileiro/2009.Dissertação (Mestrado em Educação Física). Florianópolis, PPGEF/UFSC, 2010.

OLIVEIRA, Márcio Romeu Ribas. 0 primeiro olhar: experiência com imagem na educação física escolar. Dissertação (Mestrado em Educação Física). PPGEF/UFSC. Florianópolis: 2004.

OROFINO, Maria Isabel. Mídias e mediação escolar: pedagogia dos meios, participação e visibilidade. São Paulo: Cortez, 2005. 
PAES, José Machado. Culturas juvenis, 2 ed. Lisboa: Imprensa NacionalCasa da Moeda, 2003.

PEREIRA, Rogério Santos. Avatares no secondlife:corpo e movimento na constituição da noção de pessoa on-line.Dissertação (Mestrado em Educação Física). Florianópolis, PPGEF/UFSC, 2009.

PIOVANI, Verônica Gabriela S. Escola, tecnologia e sociabilidade na educação física: intercâmbios pedagógico-culturais no âmbito do plano CEIBAL e PROUCA.Dissertação (Mestrado em Educação Física). Florianópolis, PPGEF/UFSC, 2012.

PIRES, Giovani De Lorenzi. A pesquisa em educação física e mídia nas ciências do esporte: um possível estado atual da arte. Movimento (Porto Alegre), v. 9, n. 1, p. 09-22, janeiro/abril de 2003.

PIRES, Giovani De Lorenzi; BITENCOURT, Fernando. Comunicação e mídia no âmbito do conhecimento e intervenção em Educação Física/Ciências do Esporte. In: GOELLNER, Silvana (org.). Educação Física/Ciências do Esporte: intervenção e conhecimento. Florianópolis: CBCE, 1999, p. 49-70.

PIRES, Giovani De Lorenziet al. A pesquisa em Educação Física e mídia: pioneirismo, contribuições e críticas ao "Grupo de Santa Maria". Movimento (Porto Alegre), v. 14, n. 03, p. 33-52, 2008.

PIRES, Giovani De Lorenzi (org.). Observatório da mídia esportiva: os jogos abertos de Santa Catarina. Florianópolis: Nova Letra, 2008.

. Observando o Pan Rio/2007 na mídia. Florianópolis: Tribo da llha, 2009.

O Brasil na copa, a copa no Brasil. Florianópolis; Tribo da llha, 2011. 
QUARANTA, A. M. Formação de professores de Educação Física na modalidade de educação a distância: experiências docentes no estágio supervisionado. Dissertação (Mestrado em Educação Física). Florianópolis, PPGEF/UFSC, 2011.

REZER. Ricardo. $O$ trabalho docente na formação inicial em Educação Física: reflexões epistemológicas.Tese (Doutorado em Educação Fìsica). Florianópolis: PPGEF/UFSC, 2010.

RIVOLTELLA, Pier Cesare. Mídia-educação e pesquisa educativa. Florianópolis: UFSC, Perspectiva, v.27, n.1, p. 119-140, jan./jun./2009.

PHYSICAL EDUCATION,
ANDPROSPECTS

\section{ABSTRACT}

From the recognitionof the manyinterfacesbetween Physical Education andother areas of knowledge, the text deals with the relationshipthat the fieldhas establishedthestudiesof new technologiesand media, through the concept ofMedia-Education (Physics). In thissense, it presentsmajorinroadsin the areanext to thedigital systemsof information and documentationand revisitsacademic studieswith reference to theGTTCommunications and Media/CBCEand surveys conductedbyLaboMidia/UFSC.

Keywords: Media education. Digital technologies. Search.

\section{EDUCACIÓN FISICA, MEDIA E TECNOLOGÍAS - INCURSIONES, INVESTIGACIONES Y PERSPECTIVAS}

\section{RESUMEN}

A partir del reconocimiento de las muchas interfaces de la Educación Física con otras áreas del conocimiento, el texto trata de las relaciones que el campo ha establecido con los estudios de las nuevas tecnologías y de lo media, a través del concepto de Media-Educación (Física). En este sentido, presenta las incursiones más importantes de la Educación Física brasileña, junto a los sistemas digitales de información y documentación, y vuelve a los estudios académicos con referencia a los GTT de Comunicaciones y medias/CBCE e investigaciones llevadas a cabo por LaboMidia/UFSC.

Palabras clave: Media-educación. Tecnologías digitales. Investigación.

Endereço para correspondência: giovani.pires@ufsc.br 